\title{
Seeing with the Customer's Eye: Exploring the Challenges and Opportunities of AR Advertising
}

Citation for published version (APA):

de Ruyter, K., Heller, J., Hilken, T., Chylinski, M., Keeling, D. I., \& Mahr, D. (2020). Seeing with the Customer's Eye: Exploring the Challenges and Opportunities of AR Advertising. Journal of Advertising, 49(2), 109-124. https://doi.org/10.1080/00913367.2020.1740123

Document status and date:

Published: 01/01/2020

DOI:

10.1080/00913367.2020.1740123

Document Version:

Publisher's PDF, also known as Version of record

\section{Document license:}

Taverne

\section{Please check the document version of this publication:}

- A submitted manuscript is the version of the article upon submission and before peer-review. There can be important differences between the submitted version and the official published version of record.

People interested in the research are advised to contact the author for the final version of the publication, or visit the DOI to the publisher's website.

- The final author version and the galley proof are versions of the publication after peer review.

- The final published version features the final layout of the paper including the volume, issue and page numbers.

Link to publication

\footnotetext{
General rights rights.

- You may freely distribute the URL identifying the publication in the public portal. please follow below link for the End User Agreement:

www.umlib.nl/taverne-license

Take down policy

If you believe that this document breaches copyright please contact us at:

repository@maastrichtuniversity.nl

providing details and we will investigate your claim.
}

Copyright and moral rights for the publications made accessible in the public portal are retained by the authors and/or other copyright owners and it is a condition of accessing publications that users recognise and abide by the legal requirements associated with these

- Users may download and print one copy of any publication from the public portal for the purpose of private study or research.

- You may not further distribute the material or use it for any profit-making activity or commercial gain

If the publication is distributed under the terms of Article $25 \mathrm{fa}$ of the Dutch Copyright Act, indicated by the "Taverne" license above, 


\title{
Seeing with the Customer's Eye: Exploring the Challenges and Opportunities of AR Advertising
}

\author{
Ko de Ruyter \\ King's College London, London, United Kingdom \\ University of New South Wales, Sydney, Australia
}

Jonas Heller

Maastricht University, Maastricht, The Netherlands

Tim Hilken

Maastricht University, Maastricht, The Netherlands

Matthew Chylinski

University of New South Wales, Sydney, New South Wales, Australia

Debbie I. Keeling

University of Sussex, Brighton, United Kingdom

Dominik Mahr

University of Maastricht, Maastricht, The Netherlands

This position article on augmented reality (AR) advertising offers a conceptual framework of recent scholarship on the intersection between AR technologies, advertising, and marketing

Address correspondence to Ko de Ruyter, King's Business School, King's College London, Bush House, 30 Aldwych, London WC2B 4BG, United Kingdom. E-mail: ko.de_ruyter@kcl.ac.uk

Ko de Ruyter ( $\mathrm{PhD}$, University of Twente) is a professor of marketing, King's College Business School, King's College London, and UNSW Business School, University of New South Wales.

Jonas Heller (PhD, University of New South Wales) is an assistant professor, Department of Marketing and Supply Chain Management, Maastricht University.

Tim Hilken (PhD, Maastricht University) is an assistant professor, Department of Marketing and Supply Chain Management, Maastricht University.

Mathew Chylinski (PhD, University of New South Wales) is an associate professor and honors coordinator, UNSW Business School, University of New South Wales.

Debbie Keeling ( $\mathrm{PhD}$, University of Wales) is a professor, University of Sussex Business School, University of Sussex.

Dominik Mahr (PhD, University of Antwerp) is a professor, Department of Marketing and Supply Chain Management, Maastricht University. metrics. The framework identifies theory-based building blocks for this domain alongside relevant recent examples. It proposes a conceptual case for contextualization of advertising content through AR technology. Finally, an agenda for future research in AR advertising is specified, incorporating multiple conceptual perspectives and empirical directions.

Advertisers have been aware of the contextual nature of human experience at least since the early work of Kahneman and Tversky (1982). Yet contextualization of advertising, or the ability to tailor content in real time based on the customer's physical surroundings, has thus far eluded practical applications (Mehra 2012). Partly because of technological constraints, advertisers have not tailored mass marketing communications to individual customer's physical surroundings. This potentially overlooks an important aspect of customers' brand engagement, which is oftentimes based on the processing of contextual information (Kumar and Gupta 2016; Wang 2007). With the emergence of the augmented reality (AR), however, which, with the aid of mobile computing technology, embeds digital content in the customer's view of the physical environment, contextualization of 
advertising becomes a natural extension of the technology. Although it has not been discussed at length in the marketing literature, real-time adaptation of content to an individual customer's physical surroundings is at the core of AR advertising; and it represents an important direction for future research. The aim of this position article is to draw attention to broad conceptual building blocks that frame AR as a key technology for engaging customers through contextual advertising experiences.

Despite a paucity of formal research, companies increasingly are turning to AR as a tool in their advertising strategy; in doing so, they aim to offer a higher degree of engagement with their brand communications (Lacy 2018). AR is unique among media channels because it embeds digital or holographic content (e.g., product or service visuals, animations, information, or instructions) within a customer's experience of the physical environment, interactively and in real time (Azuma et al. 2001). This not only enables customers to get a better feel for promoted products (e.g., by virtually trying on the new Michael Kors sunglasses collection through an AR banner ad); it also opens new opportunities for engagement with the advertised brands (Scholz and Smith 2016).

For instance, the fast-food chain Burger King, which has promoted flame grilling as their signature cooking method since the 1950s, recently introduced the "Burn That Ad" AR feature in its mobile app. Customers who use the feature are invited to point their smartphones at a competitor's print or billboard advertisement and virtually set these aflame. After competitor ads have been burned, a mobile coupon appears that can be exchanged for a free Whopper at one of the newly designed express windows at Burger King's nearest restaurant. This unique AR campaign connects a customer's physical environment (e.g., a print ad viewed at home, or a billboard seen on the street) with engagement with the Burger King brand.

In addition to enabling customers to engage with products, services, or brands, AR is increasingly heralded as a strategy to add value and improve incremental sales (Bona et al. 2018). For instance, Converse uses its Sampler app to stimulate purchases of the latest designer sneakers from their online catalog. By pointing a smartphone toward their feet, customers can see how the (virtual) shoes look when worn (Hilken et al. 2017; Hilken et al. 2018). Virtually trying on the shoes contextualizes the brand in an experiential way by relating it the customer's physical body and perceptions of physical surroundings. Subsequently, customers have the option to buy the pair of sneakers using a "Buy Now" function in the AR application. Contextual brand experiences potentially improve the link between advertising and sales because they fill in missing information, especially when a customer finds it difficult to generate mental imagery between the context in which he or she processes advertising information and the actual product-use context (Heller et al. 2019a). For example, with the Amazon AR app, customers can experience advertised products (e.g., a vase or other home decorations) in context, by placing three-dimensional (3D) holograms of the products in their physical surroundings (e.g., the vase on a shelf or art on a living room wall). Heller et al. (2019a) have shown that such AR-enabled product communications reduce the mental effort required to generate purchase-related imagery. Without AR, customers thus might experience difficulty imagining a product in a distant context. This is common when a customer brings a product home only to discover it looks different from how he or she imagined it at the store. With AR, however, customers offload the mental imagery to the technology, and this improves decision comfort as well as intentions to buy the product (Heller et al. 2019a).

Despite these novel and reportedly effective examples, as well as optimistic revenue projections based on clickthrough rates on banner ads (Lacy 2018), recent market surveys reveal that a large majority of customers are still uncertain about the value of AR. The use of AR is not mainstream despite significant investments in the technology (ARtillery Intelligence 2019). Many customers who have used AR also report that the applications do not live up to the hype (DigitalBridge 2017). This reveals a problem with two important advertising metrics: customer adoption and word of mouth (WOM). In our view, these problems may arise partly because of a nascent state of the AR devices, and partly because advertisers have not fully realized contextual AR advertising. Similarly, many managers report being sceptical of AR's value potential (Bona et al. 2018); they have difficulty differentiating AR from established media channels or related technologies like virtual reality (VR), ${ }^{1}$ in part because they overlook the core aspect of AR advertising, namely, the contextualization of content. This presents managers with the daunting challenge of investing in a technology whose value drivers they do not fully understand. Equally, customers, through lack of understanding and exposure, may only marginally value and perhaps not even utilize the technology. Hence, there is a pertinent managerial need for greater understanding of how customers can engage with AR advertising, and how AR advertising can drive key marketing metrics such as customer engagement, positive intent, acceptance, and diffusion of advertising information through WOM.

Beyond this clear managerial rationale, there is also a compelling need to widen the scholarly knowledge base on how AR enables contextual advertising and how such advertising can enhance customer engagement. As guidance from theorizing has remained relatively scant, we need to know whether the potential for contextual AR advertising 
is real or exaggerated. Therefore, in this article we propose a positioning framework to represent contextualization of advertising content based on AR technologies that offers a more in-depth understanding of how the design and deployment of AR translates into contextual engagement for customers and how AR engagement can encourage customers to share their experiences with others.

We seek to extend current advertising literature from three different angles. First, we summarize current research on the use of AR in advertising and synthesize existing findings to identify substantive and theoretical building blocks for AR advertising. Second, we develop a framework of how these theoretical building blocks give rise to a staged process of contextualization in AR advertising. Third, with the aim of moving the field forward, we outline a research agenda that identifies prominent opportunities for future scholarly investigations that extend theoretical perspectives within the contextualization paradigm.

\section{CONTEXTUALIZATION OF AR ADVERTISING}

The effectiveness of advertising depends in many respects on the context in which a customer experiences advertising content. A creative execution may be effective (or not) depending on small variations in the customer's immediate environment, such as viewing angle when watching TV; or whether a customer is walking or talking with a friend, listening to a radio in the background, or cooking dinner. Following Scholz and Smith (2016), who interpret $\mathrm{AR}$ as a marketing tool, we suggest that $\mathrm{AR}$ contextualization is a marketing activity in application and a design feature for the development of AR advertising (Zhao and Balagué 2015). Its aim is to generate digital affordances that influence customer behavior in physical environments. Even now, many AR applications overlook this potential. Typical AR advertisements feature addons, such as Taco Bell's Facebook feed that pops up in AR mode when a customer points his or her mobile phone at a box of Doritos; or gimmicks, such as the Starbucks Valentine's Day promotion that overlays AR images of flying hearts over a coffee cup. Unlike these add-ons and gimmicks, where interest is derived primarily based on novelty (Hilken et al. 2017), AR advertising fundamentally allows the advertiser to interact with the customer's physical surroundings. This distinguishes AR from related media like VR or online advertisements, which tailor content to digital environments. Accordingly, AR advertising is conceptually different from online and traditional media channels like $\mathrm{TV}$, print, or radio (Hilken et al. 2018). Moreover, it distinguishes itself from the well-known notion of personalization (i.e., trying to match messages with an individual customer's needs, preferences, and attitudes; Aguirre et al. 2015), because
AR contextualization engages what psychologists call bottom-up behavior control processes, where cues in the environment initiate and sustain customer behavior (Schwarz 2006), in contrast to a top-down control process through preformed attitudes.

Recent theorizing in marketing about AR has emphasized the notion of situated cognition, which describes such bottom-up behavior processes (Hilken et al. 2017). Situated cognition theorizing implies that behavior is inseparable from environment and from its so-called affordances (i.e., perceived possibilities for action) that predispose the customer to interpret information within a specific context (Wilson 2002). In a seminal work, Hilken et al. (2017) argued that the customers' "information processing is embedded in their physical environment and embodied through physical simulations and actions" (p. 885). Situating advertising information by embedding and embodying it through AR creates experiences of spatial presence, through which the customer considers AR content part of his or her physical surroundings. Spatial presence benefits customers by helping them make more accurate judgments about products, and these judgments reflect in improved marketing metrics like engagement, psychological ownership, purchase intentions, and WOM (Carrozzi et al. 2019; Heller et al. 2019a; Hilken et al. 2020).

However, researchers to date have not discussed at length the relevant implications of the way in which AR technology embeds and embodies digital content. A key implication is that AR maps the customer's physical environment. To embed digital content relative to physical objects in the customer's environment, AR scans and locates those objects in the physical space. For example, to place an AR hologram of a vase on a shelf, AR recognizes the position of the shelf as a physical object in the customer's view of his or her surroundings and adjusts the display of the AR hologram to fit that space. In effect, through such contextual mapping, AR "sees with the customer's eye," adjusting in real time the display of AR holograms to the customer's perspective. We contend that this has significant implications for the contextualization of AR advertising.

Dynamically mapping each customer's physical surroundings puts AR in a distinct category of advertising media. Current AR applications natively tailor AR display based on the customer's immediate physical environment, adjusting to lighting conditions (e.g., adjusting the brightness of the AR hologram in sunny or shaded surroundings), depth perception (by varying the size of an AR hologram), or perspective (depending if a customer is standing or sitting while viewing a hologram). So far, however, AR advertising has not leveraged this ability to tailor information to brand content. In other words, advertisers have not yet utilized the ability to tailor AR displays as an active approach for driving key marketing 
metrics. We contend this is partly because advertisers have not fully conceptualized the idea of contextualization of advertising in AR and have not explored the potential of AR's context mapping functions to make this a reality. AR contextualization requires that brand information adjust depending on the customers' perspectives of their physical surroundings. Whether a customer is walking, talking with a friend, listening to a radio in the background, or cooking dinner, AR, in principle, can adjust brand content to fit these variations in that immediate environment.

Researchers have argued that situated cognition, which underlies AR's influence on customer behavior, is a natural and in many respects preferred mode of information processing (Semin and Smith 2013), potentially making contextual AR advertising highly engaging. Yet little is known about contextual customer engagement and how it can be achieved through AR advertising. In general, Kumar and Gupta (2016) state that the focus in advertising has shifted from an emphasis on sales to that of customer engagement based on a goal of developing sustainable relationships with a customer base. While traditional advertising has been mainly about a one-directional depiction of products and services, a renewed focus on engagement is increasingly employing digital technologies in physical settings to improve interactivity of advertising activities.

Because AR enables customers to engage with digital products or services in their physical environments in an intuitive and seamless manner, it makes the contextual engagement feel real based on a sense of spatial presence (Hilken et al. 2017). That is, in AR it appears as though the customer is really trying on a new pair of Converse sneakers or burning down Burger King's competitors. Such an enhanced form of engagement, in turn, triggers a process in which the experience of spatial presence is translated into marketing metrics that reflect valued outcomes, positive intent, and WOM (Marinova et al. 2017). In the next section we propose a process of AR contextualization involving three main building blocks that distinguish contextual AR advertising from other media. Together these blocks describe contextualization according to the flow of information between (1) context mapping, (2) content matching, and (3) customer experience of spatial presence. We also suggest that these building blocks link with standard marketing metrics that advertisers may apply across various media channels to track effectiveness of contextual AR advertising against other media.

\section{CONCEPTUAL BUILDING BLOCKS FOR CONTEXTUALIZATION OF AR ADVERTISING}

\section{Context Mapping}

A critical part of AR advertising relies on the customer who uses a device such as a smartphone to scan his or her physical environment with a camera that builds a detailed map of that environment. This functionality sets AR apart from other advertising media, allowing it to locate physical objects in the customer's physical space as well as compute the customer's perspective toward these objects.

Image classification. As technology develops, computer vision can further classify physical objects to identify and interpret what they are (Restrepo-Rodríguez et al. 2019). Accordingly, by "seeing with the customer's eye," AR's real-time context mapping functionality informs an advertiser that, for example, there is a shelf at a specific location in the customer's living room. This is done by incorporating aspects of machine learning with the image data scanned by an AR device. Such information allows, for example, the IKEA Place app to recommend matching furniture items to those it recognizes in a customer's room and subsequently place them into the view of the physical environment as lifelike 3D holograms (Stevens 2019).

Gaze tracking. By tracking a customer's gaze, an advertiser also knows that the customer is currently looking at the shelf in his or her living room. Because this information is required to provide realistic representations of AR holograms that seamlessly blend with the customer's perception of physical objects, AR devices may track customer's eye movements and record fixations using back-facing cameras (van der Meulen, Kun, and Shaer 2017). This information helps an advertiser to estimate a customer's perspective toward objects in the physical environment and not only to determine what the customer is looking at currently but also to analyze a pattern of gaze fixations. As such, marketers can use gaze tracking to gain additional insights and target customers with interactive holograms that "come alive" when gazed at. For example, Microsoft's HoloLens 2 provides an interactive hologram of a desk lamp that turns on when a customer gazes at the hologram (van der Meulen, Kun, and Shaer 2017).

Real-time analytics. Performing real-time analytics on the information gathered by AR determines more than location of objects in the customer's physical environment. It allows an advertiser to learn about the motivational significance of objects, for example, through correlates of gaze fixations (Binetti et al. 2019). Consequently, by applying real-time analytics in AR, advertisers can become aware of how the customer interacts with holograms in a physical context. This, in turn, allows an advertiser to learn that a customer has placed an AR hologram of a vase on the shelf in his or her living room next to a white clock he or she really likes, for example. Currently, real-time analytics that measure distances between AR holograms and real objects, 
gaze durations, and gaze movements allow an advertiser to predict customer interactions between holographic and physical objects (Porter and Heppelmann 2017).

Affordance recognition. As the technology develops further, computer vision will eventually integrate aspects of image classification, gaze tracking, and real-time analytics to estimate the relevance and purpose of objects in the customer's physical environment. In situated cognition theory terminology, the behavioral relevance of objects in an environment represents their affordances (Stark et al. 2008). Accordingly, we propose that context mapping culminates in what we call affordance recognition by AR. That is, AR is able not only to map the locations and types of objects in the customer's living room but also to offer the possibility of learning the importance and functionality of and even the level of emotional attachment that a consumer places on objects, which gives an advertiser an unprecedented access into the customer's life. In this way, context mapping opens a new frontier of contextualized AR advertising, in which content is aligned based on detailed information about the customer's physical environment in real time and at scale.

\section{Content Matching}

Because AR enables advertisers to embed visual, 3D advertising content into the physical environment such that it forms an integral part of the customer's first-person experience, content matching refers to a real-time adaptation of advertising messages with a customer's physical surroundings. Matching is done through utilizing information from the earlier stage of context mapping to drive the contextualization of AR advertising.

Embedding. A primary requirement of content matching is the customer's suspension of disbelief that a digital depiction of a vase, for example, represents a real object within a living room (Hilken et al. 2017). Accordingly, we propose that suspension of disbelief in AR relies on an authentic visual integration, which is a customer's experience of embedding of digital content into the physical environment. When viewing such embedded digital content, customers are critically sensitive to an advertisement's ability to depict a visually appealing integration between the digital content and the physical environment. Thus, visual appeal is a higherorder element for content matching and is related to customers' experience of the aesthetics (Huang and Liao 2015), richness (Javornik 2016a, 2016b), and vividness (Yim, Chu, and Sauer 2017) of projected content. It helps customers to get a better feel for the color and texture of a virtual vase, for example, and, more importantly, believe that it is real. This is corroborated by Huang and Liao (2015) and Lee, Chung, and Jung (2015), who report that the visual appeal of AR-enabled objects in advertising is an important factor in triggering positive perceptions and, subsequently, willingness to engage with AR advertising. For example, early AR applications that projected holograms of furniture into a customer's context often lacked visual appeal. Therefore, customers would stop interacting with the application, as the holographic representations did not promote the customer's belief of being realistic within their physical environment $(\mathrm{Yu}$ et al. 2010). We propose that the appeal of visual integration is based on matching the visual components with information gathered during the context mapping stage. In this way, AR content is matched dynamically and in real time by advertisers to achieve contextualization.

Creative execution. Content matching, however, extends beyond visual integration because it enables more creative execution of advertisements, which also drives the overall visual appeal of AR advertising. While integrating digital content with the customer's perception of physical surroundings reflects the notion of embedding noted by recent studies (Hilken et al. 2017), creative execution adds an active design process to embedding that explores the role of deep contextual relationships between AR content and the customer's environment. For example, automatically altering the color of the AR vase to match the white clock on the customer's shelf is a form of creative execution in AR. Similarly, recommending additional products by placing a matching AR lamp or a chair next to an IKEA AR sofa creates value through product relationships that drive contextual visual appeal. This becomes relevant for products where visual appeal crucially depends on other objects in the customer's surroundings (Heller et al. 2019a). In this way creative execution promotes an overall look, instead of displaying a separate object. AR applications like L'Oréal's makeup sampler make use of this principle by allowing customers to virtually apply lipstick, eye shadow, and other makeup products to see how they all work together, creating an overall look before purchase.

Information fit to task. In addition to visual appeal, content matching to information gathered during the context mapping stage in AR addresses the large body of research (Gupta, Yadav, and Varadarajan 2009; Kim and Stoel 2004) that describes how human judgments rely on complex relationships of reference points (Dholakia and Simonson 2005) and contrast effects (Kahneman and Tversky 1982) between a focal task and contextual information. It has been argued that the importance of advertising content can be based on its fit with a decision 
maker's contextual information needs (Kim and Stoel 2004). For example, for customers concerned with healthy food options, KabaQ's AR application's depiction of dessert options in a restaurant menu will be visually appealing as well as render an impression of portion size and information on ingredients and calories. However, the relevance of such information varies depending on what other diners have ordered - for example, if a customer is dining with friends rather than alone. Matching content in real time to customer's contextual tasks enhances the effectiveness of AR advertising. For instance, Baeck, Yoo, and Yoon (2018) find that customers experience a stronger connection with the brand when they are able to view themselves in a virtual AR mirror and project sunglasses on images of their own faces (as opposed to viewing them on professional models). That is, customers engage differently with brand content depending on a reference point of comparison, and they assess the properties of products and services differently following information contrasts available in a specific decision situation.

We propose that content matching provides a distinct perspective on aspects of visual appeal (through embedding and creative execution) and information fit to task in the context of AR because it is driven by real-time mapping of the customer's physical environment using AR applications. Consequently, content matching in AR represents an extension of advertising to information about the customers' perceptions of their physical environments.

\section{Customer Experience}

Content matching that follows the real-time mapping of the customer's physical context leads to a unique experience of contextualization. Recent studies by Hilken et al. $(2017,2018)$ demonstrate that customers' perceptions of authentic and engaging contextual experiences in AR are commonly manifested in a sense of spatial presence. Spatial presence is based on a feeling of "nonmediation" (Lombard and Ditton 1997), such that customers fail to acknowledge the role of technology in an experience (Wirth et al. 2007). As a consequence, customers suspend their disbelief and become convinced that they are interacting with "real" objects that belong in the context of their physical surroundings (Hilken et al. 2017; Schubert 2009). That is, customers feel that the advertised pair of sneakers projected on their feet or the Yelp review projected onto a restaurant location is real, present, and relevant for them. Previous research has mainly considered presence, particularly a sense of "telepresence" (Draper, Kaber, and Usher 1998), in terms of a customer's immersion into a fully artificial digital environment (Witmer and Singer 1998) - for example, in the context of online shopping (Martínez-Navarro et al. 2019). However, an accurate understanding of spatial presence in an AR context demands a distinct conceptualization, which thus far has received only limited research attention. Specifically, and drawing on initial works (Hilken et al. 2017), we consider the key difference between notions of presence in digital environments and the experience of AR objects in physical environments is a sense of AR objects "being here (in the physical environment)" in contrast to feelings of "being there (in the virtual environment)."

In relation to contextualization, spatial presence represents a customer's perception of authentic context mapping and subsequent content matching by an advertiser. Previous research has mainly emphasized interactivity and vividness as generic advertising characteristics that lead to feelings of presence (Fiore, Kim, and Lee 2005; Fortin and Dholakia 2005), but we emphasize that in AR contexts the unique content matching features of visual appeal (from embedding and creative execution) and information fit to task offer a more conceptually nuanced and managerially relevant view of the drivers of spatial presence. Support for this conjecturing comes from presence research, which emphasizes that a sense of presence can only arise when digital content is relevant and meaningful to a user's perception and actions in the physical world (Carassa, Morganti, and Tirassa 2005). Furthermore, focused attention toward digital content, enhanced through heightened interest and involvement, is considered a crucial antecedent to sustain customers' acceptance of digital content as real within their physical surroundings (Wirth et al. 2007). Against this backdrop, embedding and creative execution-which enable visual appeal when integrated with information fit to task uniquely and in contrast to more generic advertising characteristics (e.g., interactivity or vividness) - help achieve an AR relevance that is crucial to a sense of spatial presence. In turn, spatial presence offers a possible metric to judge how a customer reacts to advertisers' attempts at contextualization in AR. While advertising in traditional media typically measures attention to a focal object-for instance, time spent viewing a YouTube advertisementwe propose that in AR advertising a customer's attention focus is better represented by the experience of spatial presence, which accounts for a relation of the focal object with the customer's physical environment (Hilken et al. 2017).

It has long been recognized that customers embrace new technologies based on the expectation of the value that they will be able to derive from them (Marinova et al. 2017). Feng and Mueller (2019) argue that from a customer perspective there are many benefits associated with AR technology. Entertainment, wayfinding, trying 
on products, and moving objects around are some of the benefits which have emerged and which led Mangiaforte (2014) to conclude that, as a result of these, the level of customer engagement with AR campaigns is far higher than with more traditional (radio and TV) advertising. The feeling of spatial presence has been shown to have a positive impact on the strength of customer beliefs about product attributes and attitudes toward advertised offerings (Fortin and Dholakia 2005). Similarly, Fiore, Kim, and Lee (2005) report a significant and positive effect of presence on a range of customer value expectations. This is corroborated across a variety of AR applications by Hilken et al. (2017) who demonstrate that spatial presence in AR has a positive impact on hedonic and utilitarian value perceptions. Consequently, a customer's experience of spatial presence provides an important metric not only to judge perceived levels of contextualization but also to depict a link between marketing outcomes and a customer's experience of contextual AR advertising.

\section{Linking AR with Marketing Metrics}

Advertisers must be able to evaluate the effectiveness of AR advertising in relation to other media. This means linking AR advertising with existing metrics that apply across media channels. For instance, Baeck, Yoo, and Yoon (2018) demonstrate a positive influence of the use of an AR-based try-on app on customer purchase intentions, which is a common metric. Furthermore, the success of AR advertising relative to other media channels can be amplified by the extent to which customers are willing to share their experiences and recommend these to others; hence, WOM becomes relevant (Heller et al. 2019a). For example, PepsiCo recently introduced the "Unbelievable" campaign, which featured an ARenhanced bus shelter in London; this campaign led to a great deal of positive buzz across various social media. A YouTube clip explaining the campaign attracted 2 million views and 24,000 shares in just seven days. This implies that common marketing metrics should be tracked among media channels to understand whether the unique building blocks that distinguish AR advertising also improve the effectiveness of advertising.

\section{Privacy Constraints}

Contextual AR advertising heralds a potential boon for marketers and customers alike, which can lead to improved marketing metrics. However, the process of contextualization also poses a potential drawback. The same technology that enables contextualization invariably infringes on customer privacy. This can be problematic, especially in traditionally private settings, such as the customer's living room. Many customers who are aware their online behavior can be tracked by advertisers seeking to use personal information to improve online content (Kumar and Reinartz 2018) may be equally concerned about contextualization through AR. Context mapping gathers information about the customer's intimate physical surroundings. Accordingly, contextualization of AR advertising extends the notions of the privacy paradox (Aguirre et al. 2015; Rauschnabel, He, and Ro 2018) to physical settings. On one hand, sharing private information improves an advertiser's ability to match content based on the customer's physical environment, which leads to improved services that benefit the customer. On the other hand, a seamless experience of spatial presence sends a signal that the advertiser potentially has access to private information about the customer's physical environment. A concern for privacy protection interferes with contextual AR advertising in two important ways. First, it restricts access to information about private spaces limiting the advertiser's ability to achieve content matching. Second, it moderates the link between the experience of spatial presence and marketing metrics. Because for strongly privacyconcerned customers the experience of spatial presence implies that their privacy is being infringed, these customers may be less (rather than more) likely to respond positively to experiences of spatial presence.

Privacy in AR contexts is poorly understood in the current literature. We propose, however, that privacy poses a critical constraint on AR contextualization, and it necessitates explicit consideration within the paradigm of AR advertising contextualization. Illustratively, the early failure of Google Glass could in part be attributed to customers' privacy concerns. Because Google Glass not only recorded contextual information belonging to its user but also captured information about anyone in the user's field of view, Google Glass became socially unacceptable (Haque 2015). To avoid a similar fate, AR contextualization requires strong privacy protection, anonymization of data, demarcation of public versus private spaces, and social norms that can drive public policy to regulate applications of AR in advertising.

Figure 1 depicts proposed relationships between the building blocks of the process of contextual advertising, including context mapping, content matching, and customer experiences of spatial presence that integrate to drive media effectiveness (i.e., marketing metrics). Table 1 provides an overview of AR advertising configurations and their relationship with our theory-based building blocks.

\section{A RESEARCH AGENDA FOR AR ADVERTISING}

The theory-based process outlined in this article offers an exploration of unique features of AR that enable 
Contextualization of AR Advertising

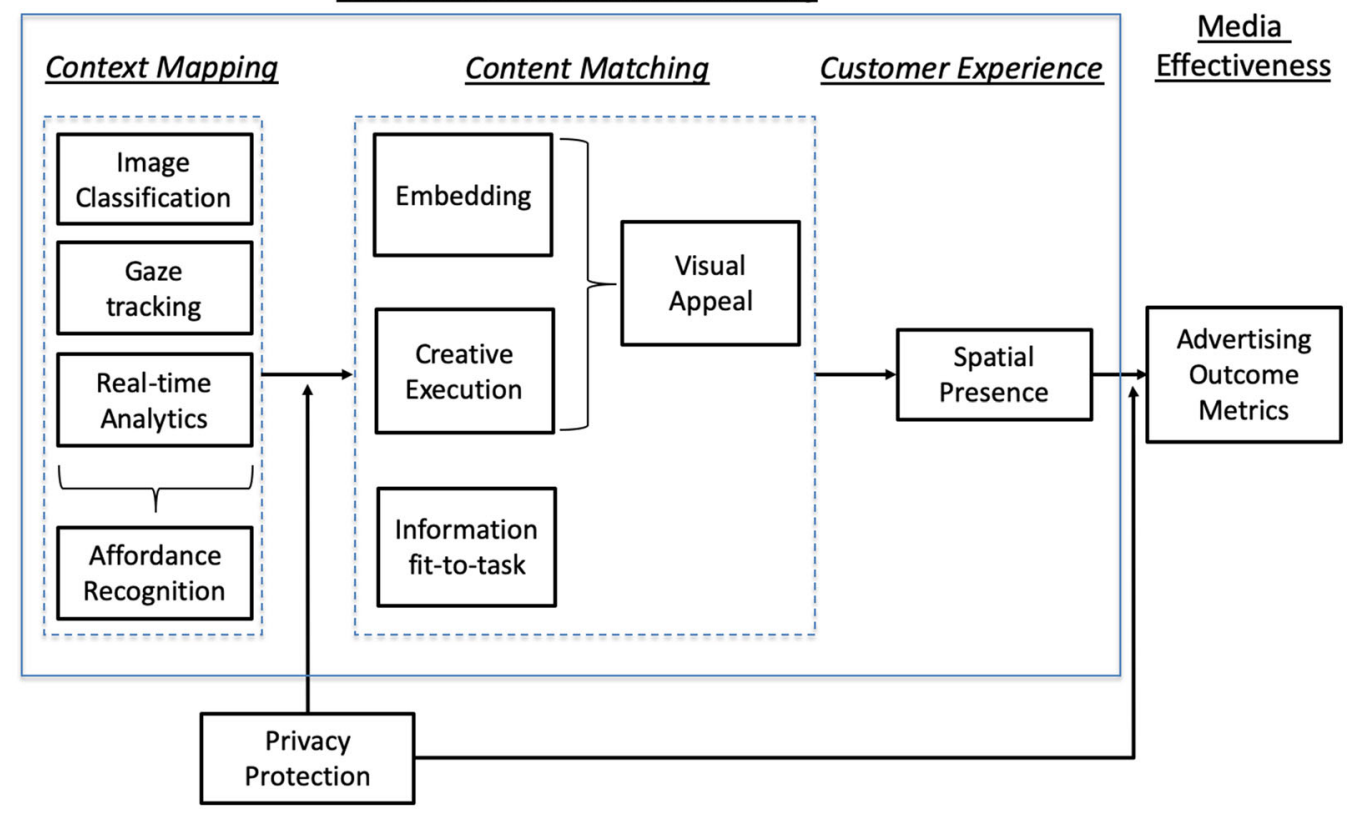

FIGURE 1. Conceptual framework.

contextualization of advertising. In Figure 1, we illustrate a conceptual framework that describes a research paradigm for contextual AR advertising. Our framework organizes conceptual building blocks that can stimulate research in this domain. The use of AR for advertising and its impact on customer engagement and behavior is and will continue to be a complex phenomenon. This is why it seems pertinent for advertising scholars to widen their understanding, deepen the knowledge base and advance managerial insights by developing theory-driven models; and, through research, validate these by means of rigorous empirical explorations. The aim of the next section is to provide guidance to future theorizing by offering a number of recommended research directions that align with the building blocks of contextual AR advertising paradigm.

\section{Future Research Agenda for Context Mapping}

Context mapping should be a significant topic of research in AR advertising. It is a unique aspect of $A R$ technology, which requires further advances in understanding of real-time marketing analytics, image classification, and ultimately application of artificial intelligence (AI) in advertising. While text-mining techniques have been widely applied to online advertising research, contextual AR advertising requires a focus on image analysis. Researchers need to advance their techniques of image mining (Villarroel Ordenes et al. 2019). Moreover AR requires real-time analytics based on image classification to interpret contextual information on the fly.
Researchers should broaden the definition of context mapping beyond the mere position of objects in the customer's physical surroundings. More broadly, context mapping involves patterns of customer behavior that give meaning to objects in the environment. In this respect image classification is situated, yet current analytics overlook this point. Laboratory studies can aid the analytical work by investigating the situated interaction of customers with so-called environmental affordances. According to situated cognition theory, physical objects in a customer's surroundings predispose behavior in predictable ways (i.e., they create contextual affordances) based on implied functions of these objects and the customer's tasks (Semin and Smith 2013). For example, a couch in a living room predisposes customers to sit down and linger, and this can influence how customers process brand information. Mathmann et al. (2017) showed that customers who sit (versus move) during decision making are more likely to evaluate information in detail. Thus, research into context mapping could help managers interpret patterns of customer behavior by following a customer's control of the visual perspective in AR. Because AR advertising sees with the customer's eye, context mapping needs to understand how patterns of gaze fixations link to customer's tasks and predict behavior. Currently, managers might struggle to interpret AR gaze patterns. For example, some researchers proposed that returning the gaze back to an object may reflect accumulation of evidence and hence preference formation; others argue the same patterns reflect customers' established preferences because people look at what they already like (Semmelmann and 


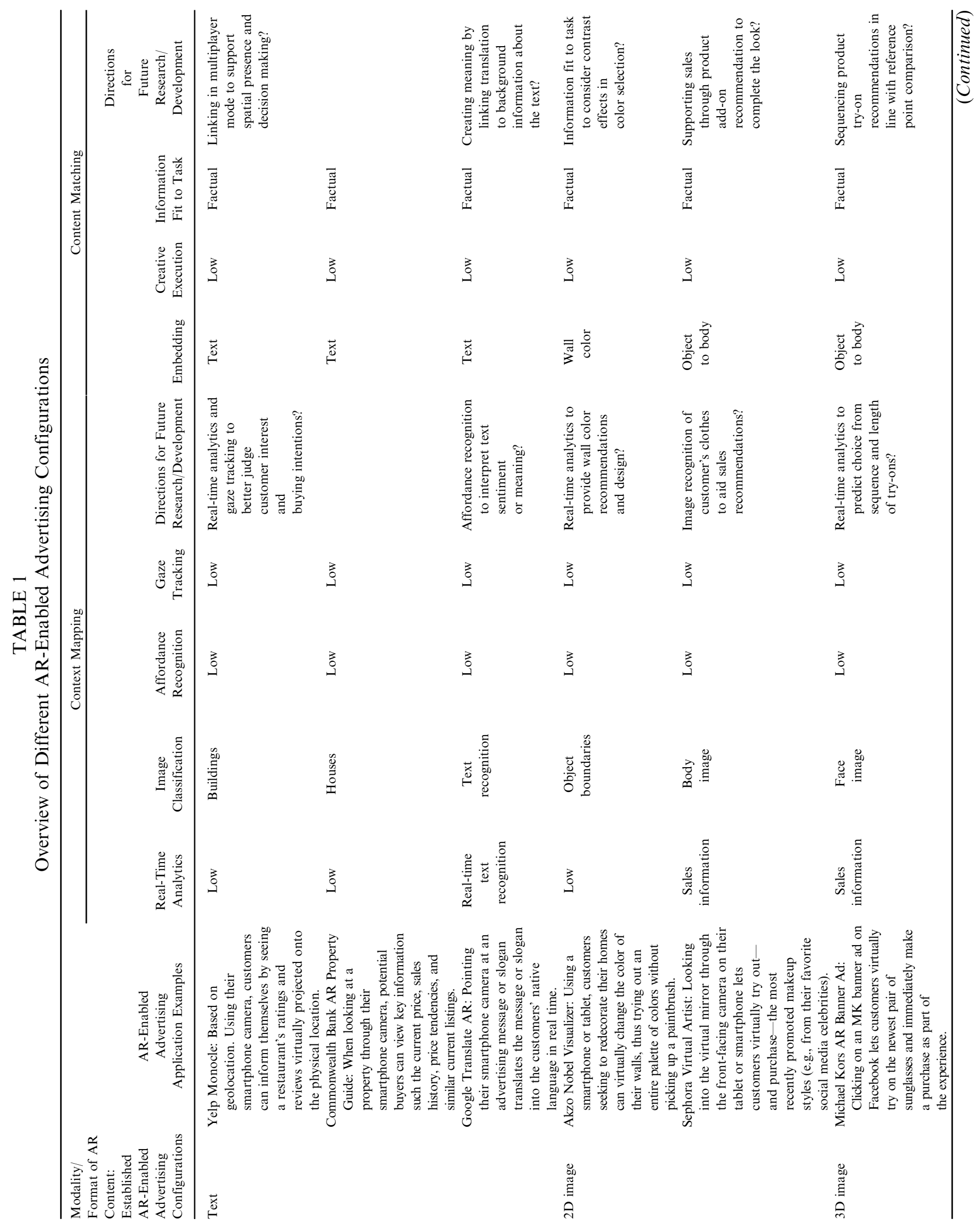




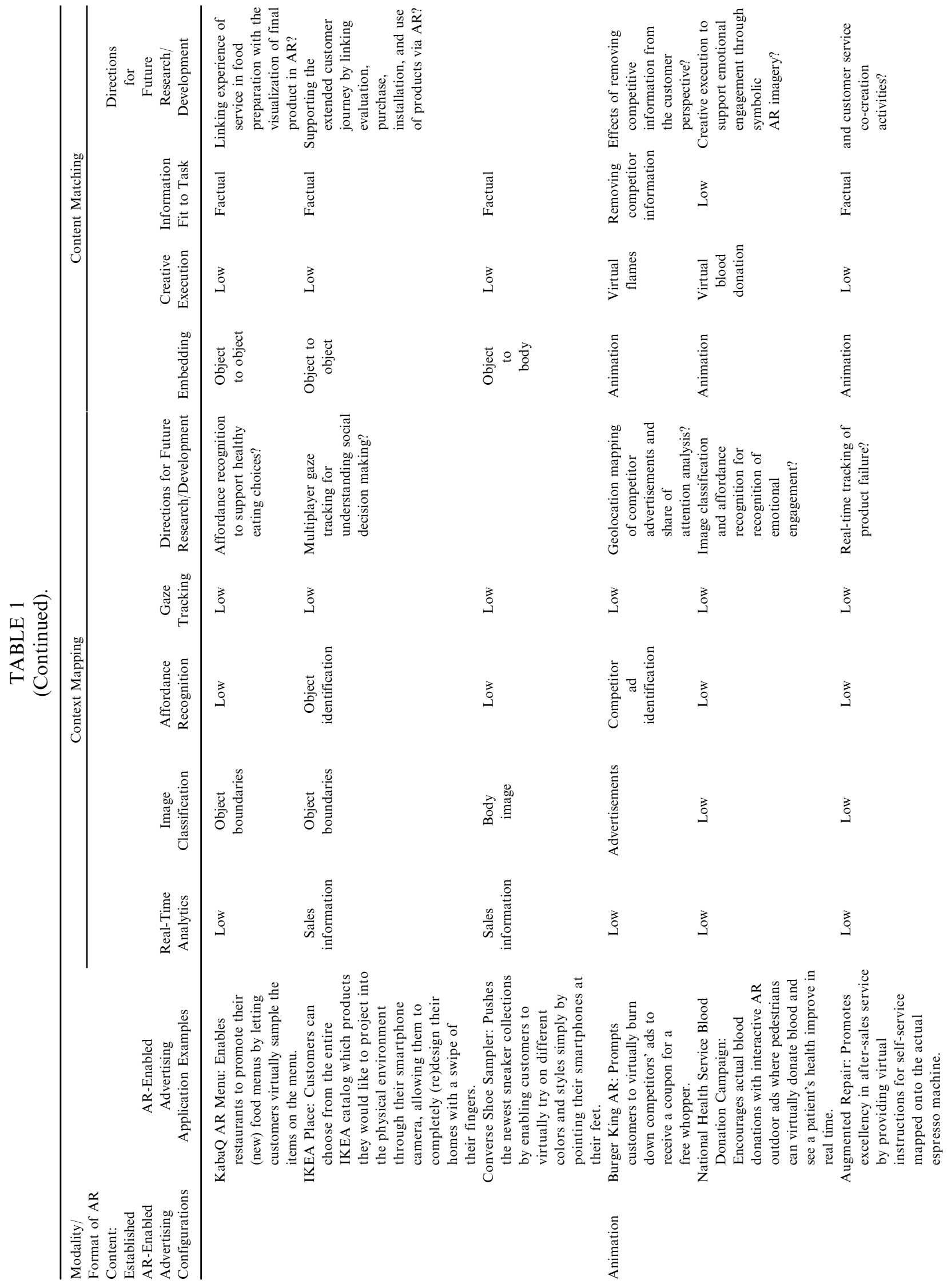



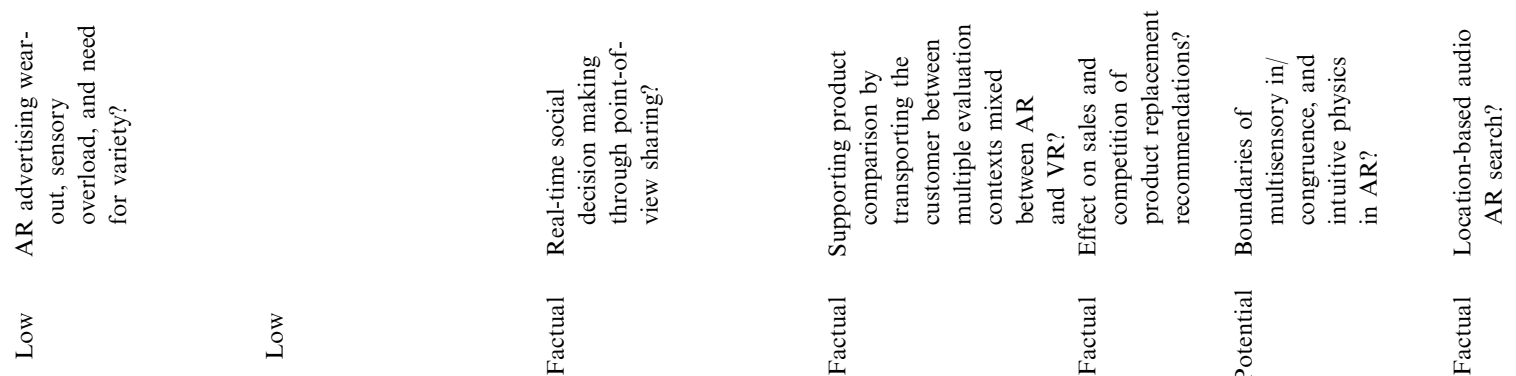

吾

丞

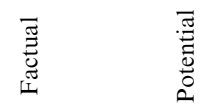

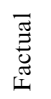

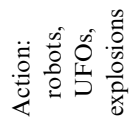

3.

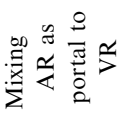

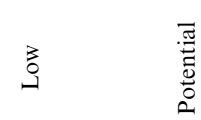

章

空

$\stackrel{8}{\frac{8}{5}}$

量

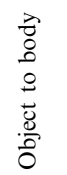

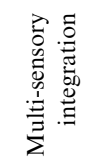

穿

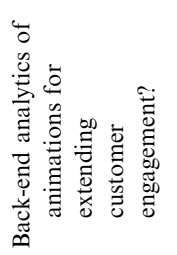

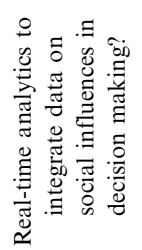

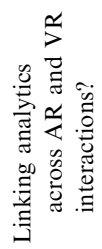

3

zo

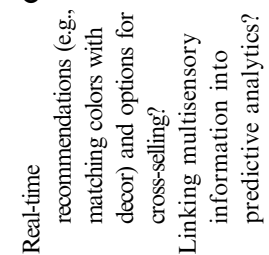

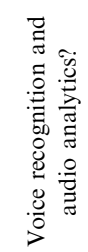

?3.0

30

尊芯

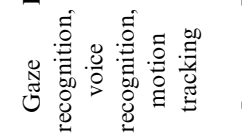

3.

?3

3

ำ

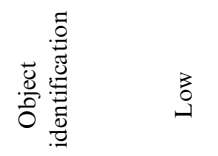

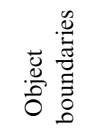

总

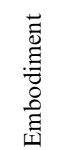

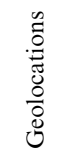

कृ

ב⿱ ב⿱

$\vdots$

聯递

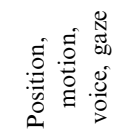

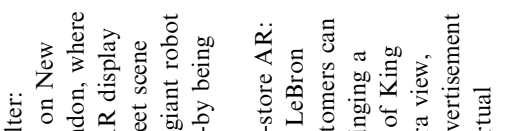

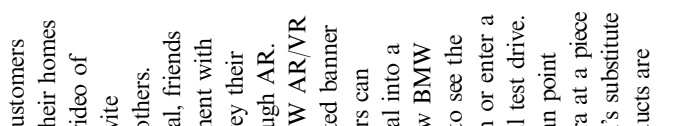

齐总。

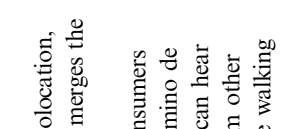

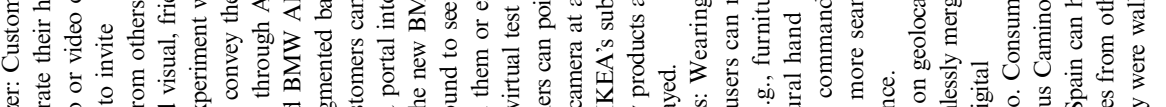

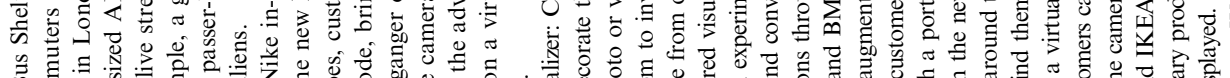

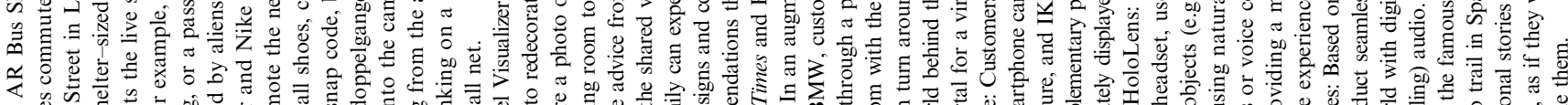

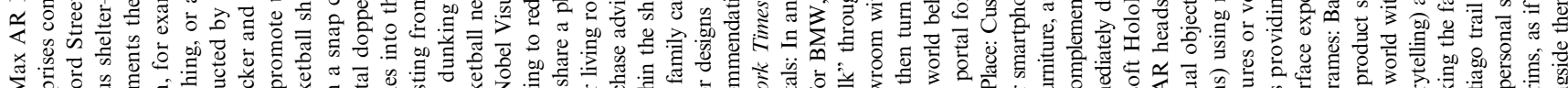

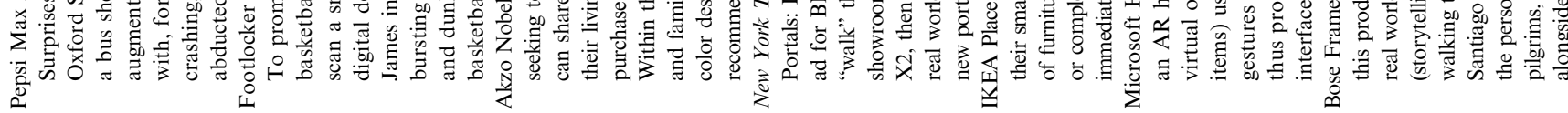

哥

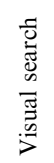

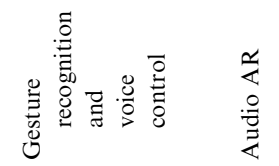


Weigelt 2018). Linking patterns of customers' visual perspectives with information about objects in the physical environment may allow improved classification based on situated relevance of objects during context mapping.

Future studies should also deploy experimental designs to empirically assess cause and effect relationships between pertinent affordance-behavior relationships to gauge the impact of firsthand experience in lab studies, as well as experimental field studies, to uncover more complex patterns between customer behavior and contextual information. In such designs it would be advisable to account for both observed heterogeneity and the impact of boundary conditions, such as visual or verbal information processing styles that customers may have (c.f., Hilken et al. 2017). Moreover, because AR provides significant opportunities for field experimentation, researchers will be able to assess the different ways in which context mapping can be extended in different situations to enable the full conversion funnel and gauge its impact on decision comfort and confidence as well as actual choice behavior.

As a result of growing sophistication of hardware (i.e., devices) and software, future research may focus not only on how customers interact with embedded virtual objects in their natural environment but also on how they search digital offerings through object recognition. For instance, Shazam-like software applications of AR might provide customers with information on clothing or fashion accessories that other people wear. Relatedly, IKEA has recently included a visual search function in its app. Customers can point their smartphone camera at a piece of furniture, and IKEA's substitute or complementary products are immediately displayed. In terms of hardware, many of the current AR tools are based on simulating physical control through touch-screen interactions (e.g., moving virtual sofas with the swipe of a finger). Next generation AR functionalities (e.g., Microsoft's HoloLens or Vuforia's Chalkboard) allow gesture recognition or voice activation, which may enable a higher degree of context mapping between physical interactions with an object through an AR interface. Future work should monitor the impact of these technological advances on both the potential for expanding context analytics and the effectiveness of context mapping in AR.

\section{Future Research Agenda for Content Matching}

AR advertising provides expanded opportunities for research on creative content design. Currently, we do not know the most effective combinations of information fit to task and visual appeal in creative execution. Heller et al. (2019b) showed how congruent multisensory information is integrated in AR. Yet, many aspects of sensory integration in AR remain to be investigated. For example, while it is expected that combinations of multisensory stimuli can drive attention focus (e.g., Toohey's deer ad), the boundaries of sensory congruence (e.g., information that contrasts with the background context, or sensory modalities that provide different information) are not well understood in AR. Balancing content integration with attention capture is an important area of research in contextual AR advertising. Similarly, because AR relies on deep sensory integration within some but not all of the sensory modalities (e.g., visual and audio but not taste or smell), applications like the KabaQ's AR restaurant app may need to investigate creative ways to integrate AR information across different sensory modalities like taste or smell, or to convey abstract information like healthy eating choices, for example.

Content matching research should also expand beyond visual integration in AR. To date many applications have attempted to closely replicate intuitive physics (Kubricht, Holyoak, and $\mathrm{Lu} 2017$ ) that provide realistic embodied representation of AR objects embedded in the physical environment (Heller et al. 2016). For example, AR holograms typically do not pass through solid objects; they exhibit object permanence and move in straight lines over short distances. Yet there is anecdotal evidence that during the brief Pokémon Go AR craze (Kumparak 2017) some players would turn off AR graphics to improve performance in the game. Currently, we do not know to what extent close rendering of intuitive physics is necessary for efficient and effective interaction in AR, and if realistic versus simplified forms of interaction (e.g., teleportation of AR holograms) could improve customer engagement.

The spectrum of potential in AR extends beyond information integration through embedding, yet little is known about the extent to which content matching can be enhanced by creative execution. Would customers accept more creative interpretations (like Australia's Toohey's Dry advertisements that showed a customer's tongue leave his mouth to grab a beer) that in AR become significantly more real among their physical surroundings? Or would cartoon physics (e.g., objects that hover briefly before falling to the ground) be a more fun and engaging form of content matching in AR? Similarly, while in general we know that product evaluations can be influenced by information fit to task, there is a paucity of research on creative execution of reference point and contrast effects in AR advertising. Specifically, would a customer respond differently to AR advertising knowing that information is being adapted depending on the task and the point of comparison during AR interaction? The diagnosticity of different types of information formats and various visual execution styles in advertising could also vary 
across different product and service categories or across different stages in the purchase funnel (e.g., presales versus aftersales). More research is needed to investigate such boundary conditions of content matching.

Because the effects of creative execution may vary depending of the stage of decision making, there is further scope for testing the impact of contextual AR advertising along various steps in the customer journey (e.g., need recognition and awareness, evaluation of options, postpurchase WOM). Initial studies show that AR is generally perceived to be more informative (Yaoyuneyong et al. 2016). Future research is needed to identify which specific content and what AR modalities are most effective in different stages of the customer journey. Applications such as Yelp's Monocle or social media platform Mirage allow customers to tag physical locations with digital messages, animations, and/or ratings. In addition to visual aspects, content matching is branching out by integrating related technologies. For instance, based on geolocation data, AR audio applications like Bose's Frames seamlessly merge real-world and digital (storytelling) audio. Customers who walk the famous Camino de Santiago trail in Spain can hear the personal stories from other pilgrims - just as if they were walking alongside them (Swant 2019). Future studies could focus on the effects of various types of localized and targeted modalities to improve content matching in combination with geotagging technology, while evaluating both the pros and cons of such approaches (Čaić et al. 2015).

\section{Future Research Agenda for Customer Experience of Contextualization}

While this article followed an established view that marketers provide AR applications that allow customers to control content in a certain context (Scholz and Smith 2016), the topic of control of contextualization can be approached from additional angles. Future research should also investigate how much control marketers should enable for contextual AR applications to ensure that customers engage in the desired interactions. While some AR applications require customers to follow exact steps when interacting with AR content (e.g., Burger King's "Burn That Ad"), others give customers more freedom in controlling AR content (e.g., IKEA Place). Future research should investigate whether this control is context dependent and which contexts require more (or less) control in the customers' hands (van Esch et al. 2016); or, indeed, whether continuing advancements in technology will lead us to challenge the fundamental notion of control and whether this will be supplanted by notions of collaboration.
As with the introduction of many technological platforms, future research should examine how contextual AR advertising can be applied optimally in combination with related technologies. For instance, VR that immerses customers in fully digital environments can achieve similar objectives of promoting brands or exposing customers to novel experiences. However, currently managers have not delineated advertising strategies for VR versus AR. For example, auto manufacturer Nissan recently launched its "See the Unseen" AR campaign, which introduced its advanced vehicle safety technologies by means of Star Wars movie characters. The well-known characters showed new technological features to prospective car buyers that are not directly visible and hence not salient to customers. The campaign enjoyed wide popularity and outperformed other advertising campaigns across traditional and digital media in terms of brand awareness and favorability. In parallel, Nissan used their "Tech-Drive" VR campaign, where customers become immersed in a digital environment simulating the experience of using Nissan's drive assistance technologies, like the Pro-Pilot. Researchers can build on the notions of contextualization to explore similarities and differences between AR and VR technologies in advertising. These technologies may share many of the context mapping and context matching principles, but they critically differ in the customer's awareness of contextualization. That is, the relation of the first-person awareness of contextual surroundings is different in AR versus VR. Researchers should explore how AR technologies focus first-person awareness on digital information in the customer's physical surroundings, versus VR technologies that move the customer's first-person awareness into a fully digital context. Given the immersive nature of the AR and VR campaigns, both technologies could be linked through a narrative context based on a shared storytelling theme. For example, Nissan might relate their AR and VR campaigns using the Star Wars characters, who would appear across the different reality experiences. Future research should embark on examining the creative role of ARbased advertising and its integration with VR within the transmedia storytelling and narrative persuasion as expanded notions of presence.

The research on expanding the notion of presence should also consider social aspects of AR (Hilken et al. 2020). Current understanding of spatial presence in AR is restricted to aspects of the physical environment, which misses influence on the customer in physical settings. For example, Facebook has invested in AR and VR technologies (Constine 2017). As social AR technologies develop, AR advertising will inevitably integrate with social networks. Taking into account that purchase decisions are increasingly shared with friends and peers through social 
media apps, future research needs to assess how AR advertising can be designed to account for expanded notion of social presence to support shared decision opportunities and perhaps cocreation. For instance, Akzo Nobel's Visualizer app not only is a vehicle for displaying an extensive range of color wall paints but also enables customers to jointly decide on what color to choose by exchanging visuals of color designs. In parallel, research needs to be undertaken in collaborative business-to-business marketing as well. For instance, how can AR advertising bring together architects, designers, builders, and end customers in creating bathroom designs? As this extends the role of advertising into the new realm of shared decision making, guidance from future research is much needed. According to Feng and Mueller (2019), future research should moreover examine the effect of AR advertising across different cultures as an important moderator of optimal configurations of AR. That is, AR affordances may have different perceived values when viewed through diverse cultural lenses.

\section{Future Research Agenda for Privacy Protection}

While the theory-based building blocks hold promise for the future of contextual AR advertising, and its applications offer relevant benefits to customers, AR may also produce significant security, transparency, and privacy concerns, as well as produce a range of ethical issues. There is a paucity of research that explicitly addresses these concerns. As the technology is equipped to record data continuously and mix objects and information with observable reality, a number of unique concerns may potentially conflict with customer interests and regulatory boundaries. Data that are registered by AR applications are not only personal but also collected and contextualized in real time. For instance, privacy concerns relate to the fact that a customer's identity is tagged (e.g., via facial recognition software) to geolocations (e.g., personal environments) and ads that he or she is looking at in real time. Also, through recognition functionalities, AR offers the opportunity to record others and pervasively store sensory information without their knowledge. For example, facial recognition can seamlessly be coupled with private or social media-based information. Thes data could be accessed by many stakeholders, including application owners, advertisers, and market researchers. As such, future research is needed to understand how to provide strong privacy protections through encryption and anonymization of data. Our framework identifies privacy protections as a crucial moderator of the ability of advertisers to contextualize AR content and the effect of contextualization on marketing metrics. Concerns over privacy protection have been discussed in relation to the high-profile failure of Google Glass to gain mainstream adoption, for example (Haque 2015). Research is needed on how stakeholders can aim for "privacy by design" in contextual AR advertising by incorporating privacy and security compliance from the ideation stages of campaigns. Insights are also needed to assess the extent to which privacy, transparency, and security may act as adoption barriers to AR advertising by consumers and/or what trade-offs they are willing to make for greatly enhanced interactivity, functionality, and relevance.

In conclusion, AR is creating a host of exciting new avenues for advertising to enhance customer engagement and ultimately advertising effectiveness. To make sure that this potential becomes a reality we need to tread carefully and with insights augmented by robust and relevant research. We hope that this position article will motivate and invite researchers to take a step in this direction.

\section{Note}

1. Unlike AR, VR transports a customer's perception into a fully digital environment devoid of real-time interaction with the physical context. Consequently, VR is distinguished because it does not provide contextualization; content in VR is independent of the customer's physical surroundings.

\section{REFERENCES}

Aguirre, Elisabeth, Dominik Mahr, Dhruv Grewal, Ko de Ruyter, and Martin Wetzels (2015), "Unraveling the Personalization Paradox: The Effect of Information Collection and Trust-Building Strategies on Online Advertisement Effectiveness," Journal of Retailing, 91 (1), 34-49. doi:10.1016/j.jretai.2014.09.005

ARtillery Intelligence (2019), "Mobile AR: Usage and Customer Attitudes, Wave II," https://artillry.co/artillry-intelligence/mobile-arusage-and-consumer-attitudes-2019/ (accessed January 20, 2020).

Azuma, Ronald, Yohan Baillot, Reinhold Behringer, Stephen Feiner, Simon Julier and Blair MacIntyre (2001), "Recent Advances in Augmented Reality," IEEE Computer Graphics and Applications, 21 (6), 34-67. doi:10.1109/38.963459

Baeck, Tai Hyun, Chan Yun Yoo, and Sukki Yoon (2018), “Augment Yourself through Virtual Mirror: The Impact of Self-Viewing and Narcissism on Customer Responses," International Journal of Advertising, 37 (3), 421-39. doi:10.1080/02650487.2016.1244887

Binetti, Nicola, Tianchang Cheng, Isabelle Mareschal, Duncan Brumby, Simon Julier, and Nadia Bianchi-Berthouze (2019), "Assumptions about the Positioning of Virtual Stimuli Affect Gaze Direction Estimates during Augmented Reality Based Interactions," Scientific Reports, 9 (1), 1-9. doi:10.1038/s41598-019-39311-1

Bona, Carmen, Martin Kon, Lara Koslow, David Ratajczak, and Michael Robinson (2018), "Augmented Reality: Is the Camera the Next Big Thing in Advertising?," Boston Consulting Group, April 3, https://www.bcg.com/publications/2018/augmented-reality-is-cameranext-big-thing-advertising.aspx (accessed April 14, 2019).

Čaić, Martina, Dominik Mahr, Elizabeth Aguirre, Ko de Ruyter, and Martin Wetzels (2015), “'Too Close for Comfort': The Negative Effects of Location-Based Advertising," in I. Banks, P. De 
Pelsmacker, and S. Okazaki, eds., Advances in Advertising Research, vol. 5, Wiesbaden, Germany: Springer Gabler, 103-11.

Carassa, Antonella, Francesca Morganti, and Maurizio Tirassa (2005), "A Situated Cognition Perspective on Presence," in Proceedings of the Annual Meeting of the Cognitive Science Society, 27 (27), 384-89.

Carrozzi, Amelia, Mathew Chylinski, Jonas Heller, Tim Hilken, Debbie I. Keeling, and Ko de Ruyter (2019), "What's Mine Is a Hologram? How Shared Augmented Reality Augments Psychological Ownership," Journal of Interactive Marketing, 48, 71-88. doi:10.1016/j.intmar.2019.05.004

Constine, Josh (2017), "Facebook Launches Augmented Reality Camera Effects Developer Platform," Techcrunch, April 18, https://techcrunch.com/2017/04/18/facebook-camera-effects-platform/ (accessed January 20, 2020).

Dacko, Scott G. (2016), "Enabling Smart Retail Settings via Mobile Augmented Reality Shopping Apps," Technological Forecasting and Change, 124, 243-56. doi:10.1016/j.techfore.2016.09.032

Davis, Fred D. (1989), "Perceived Usefulness, Perceived Ease of Use, and User Acceptance of Information Technology," MIS Quarterly, 13 (3), 319-40. doi:10.2307/249008

Dholakia, Utpal M., and Itamar Simonson (2005), "The Effect of Explicit Reference Points on Consumer Choice and Online Bidding Behavior," Marketing Science 24, 2, 206-17. doi:10.1287/mksc.1040. 0099

DigitalBridge (2017), "Augmented Reality: Changing the Face of Retail," http://digiralbridge.eu/download-our-newreport-augmented reality-changing-the-face-of-retail (accessed on April 9, 2019).

Draper, John V., David B. Kaber, and John M. Usher (1998), "Telepresence," Human Factors, 40 (3), 354-75. doi:10.1518/ 001872098779591386

Feng, Yang, and Barbara Mueller (2019), "The State of Augmented Reality Advertising around the Globe: A Multi-Cultural Content Analysis," Journal of Promotion Management, 25 (4), 453-75. doi:10. $1080 / 10496491.2018 .1448323$

Fiore, Ann Marie, Jihyun Kim, and Hyun-Hwa Lee (2005), "Effect of Image Interactivity Technology on Customer Responses toward the Online Retailer," Journal of Interactive Marketing, 19 (3), 38-53. doi: 10.1002/dir.20042

Fortin, David R., and Ruby Roy Dholakia (2005), "Interactivity and Vividness Effects on Social Presence and Involvement with a WebBased Advertisement," Journal of Business Research, 58 (3), 387-96. doi:10.1016/S0148-2963(03)00106-1

Gupta, Pranjal, Manjit S. Yadav, and Rajan Varadarajan (2009), "How Task-Facilitative Interactive Tools Foster Buyers' Trust in Online Retailers: A Process View of Trust Development in the Electronic Marketplace," Journal of Retailing, 85 (2), 159-76. doi:10.1016/j.jretai.2009.02.001

Haque, Umar (2015), “Google Glass Failed Because It Just Wasn't Cool," Harvard Business Review, January 30, https://hbr.org/2015/ 01/google-glass-failed-because-it-just-wasnt-cool (accessed April 9, 2019).

Harrison-Walker, L. Jean (2001), "The Measurement of Word-ofMouth Communication and an Investigation of Service Quality and Customer Commitment As Potential Antecedents," Journal of Service Research, 4 (1), 60-75. doi:10.1177/109467050141006

Heller, Jonas, Mathew Chylinski, Ko de Ruyter, Dominik Mahr, and Debbie I. Keeling (2019a), "Let Me Imagine That for You: Transforming the Retail Frontline through Augmenting Customer Mental Imagery Ability," Journal of Retailing, 95 (2), 94-114. doi:10. 1016/j.jretai.2019.03.005

- - - - - $\longrightarrow$, and - $(2019 \mathrm{~b})$, "Touching the Untouchable: Exploring Multi-Sensory Augmented Reality in the Context of Online Retailing," Journal of Retailing, 95 (4), 219-34.
Esch, Tim Hilken, and Dominik Mahr (2016), "Topology of Augmented Commerce: The State and Directions for Future Research," in Proceedings: Australian and New Zealand Marketing Academy Conference (ANZMAC) 2016: Marketing in a PostDisciplinary Era, Christchurch, New Zealand: University of Canterbury, 88-95.

Hilken, Tim, Ko de Ruyter, Mathew Chylinski, Dominik Mahr, and Debbie I. Keeling (2017), "Augmenting the Eye of the Beholder: Exploring the Strategic Potential of Augmented Reality to Enhance Online Service Experiences," Journal of the Academy of Marketing Science, 45 (6), 884-905. doi:10.1007/s11747-017-0541-x

_- Jonas Heller, Mathew Chylinski, Debbie I. Keeling, Dominik Mahr, and Ko de Ruyter (2018), "Making Omnichannel an Augmented Reality: The Current and Future State of the Art," Journal of Research in Interactive Marketing, 12 (4), 509-23. doi:10. 1108/JRIM-01-2018-0023

—. Debbie I. Keeling, Ko de Ruyter, Dominik Mahr, and Mathew Chylinski (2020), "Seeing Eye to Eye: Social Augmented Reality and Shared Decision Making in the Marketplace," Journal of the Academy of Marketing Science, 48 (2), 143-64. doi:10.1007/s11747019-00688-0

Huang, Tseng-Lung, and Shuling Liao (2015), "A Model of Acceptance of Augmented-Reality Interactive Technology: The Moderating Role of Cognitive Innovativeness," Electronic Commerce Research, 15 (2), 269-95. doi:10.1007/s10660-014-9163-2

Javornik, Anna (2016a), “Augmented Reality: Research Agenda for Studying the Impact of Its Media Characteristics on Customer Behaviour," Journal of Retailing and Customer Services, 30 (May), 252-61. doi:10.1016/j.jretconser.2016.02.004

- (2016b), "It's an Illusion, But It Looks Real! Customer Affective, Cognitive, and Behavioural Responses to Augmented Reality Applications," Journal of Marketing Management, 32 (9-10), 987-1011.

Kahneman, Daniel, and Amos Tversky (1982), "The Psychology of Preferences," Scientific American, 246 (1), 160-73. doi:10.1038/scientificamerican0182-160

Kim, Soyoung, and Leslie Stoel (2004), "Dimensional Hierarchy of Retail Website Quality," Information and Management, 41 (5), 619-33. doi:10.1016/j.im.2003.07.002

Kubricht, James R., Keith J. Holyoak, and Honging Lu (2017), "Intuitive Physics: Current Research and Controversies," Trends in Cognitive Sciences, 21 (10), 749-59. doi:10.1016/j.tics.2017.06.002

Kumar, Vijay, and Shaphall Gupta (2016), "Conceptualizing the Evolution and Future of Advertising," Journal of Advertising, 45 (3), 302-17. doi:10.1080/00913367.2016.1199335

- - and Werner Reinartz (2018), Customer Relationship Management, Berlin: Springer.

Kumparak, Greg (2017), "Pokémon Go Gets a New and Improved Augmented Reality Mode (But Only on iOS)," TechCrunch, December 20, https://techcrunch.com/2017/12/20/pokemon-go-getsa-new-and-improved-augmented-reality-mode-but-only-on-ios/ (accessed January 15,2020$)$.

Lacy, Lisa (2018), "Can Augmented Reality Breathe New Life into Banner Ads?," Adweek April 20, https://www.adweek.com/digital/ can-augmented-reality-breathe-new-life-into-banner-ads/ (accessed April 15, 2019).

Lee, Hyunae, Namho Chung, and Timothy Jung (2015), "Examining the Cultural Differences in Acceptance of Mobile Augmented Reality: Comparison of South Korea and Ireland," in Information and Communication Technologies in Tourism 2015, Iis Tussyadiah and Alessandro Inversini, eds., Cham, Switzerland: Springer, 477-91.

Lombard, Matthew, and Theresa Ditton (1997), "At the Heart of It All: The Concept of Presence," Journal of Computer-Mediated 
Communication, 3 (2), published electronically June 23, 2006, doi:10. 1111/j.1083-6101.1997.tb00072.x

Mangiaforte, Lauren B. (2014), "Why Augmented Reality Will Be Huge in 2015," Business 2 Community, December 3, https://www.business2community.com/brandviews/newscred/augmented-reality-marketingwill-huge-2015-01086301 (accessed April 9, 2019).

Marinova, Detelina, Ko de Ruyter, Ming Hui Huang, Matt Meuter and Goutham Challagalla (2017), "Getting Smart: Learning from Technology-Empowered Frontline Interactions," Journal of Service Research, 20 (1), 29-42. doi:10.1177/1094670516679273

Martínez-Navarro, Jesus, Enrique Bigné, Jaime Guixeres, Mariano Alcañiz, and Carmen Torrecilla (2019), "The Influence of Virtual Reality in E-Commerce," Journal of Business Research, 100 (July), 475-82. doi:10.1016/j.jbusres.2018.10.054

Mathmann, Frank, Mathew Chylinski, Edward Tory Higgins, and Ko de Ruyter (2017), "Every Step Counts: When Physical Movement Affects Perceived Value," Journal of Retailing and Consumer Services, 39 (November), 279-85. doi:10.1016/j.jretconser.2017.08. 007

Mehra, Pankaj (2012), "Context-Aware Computing: Beyond Search and Location-Based Services," IEEE Internet Computing, 16 (2), 12-16. doi:10.1109/MIC.2012.31

Porter, Michael E., and James E. Heppelmann (2017), "Why Every Organization Needs an Augmented Reality Strategy," Harvard Business Review, 95 (6), 46-57.

Rauschnabel, Philipp A., Jun He, and Young K. Ro (2018), "Antecedents to the Adoption of Augmented Reality Smart Glasses: A Closer Look at Privacy Risks," Journal of Business Research, 92 (November), 374-84. doi:10.1016/j.jbusres.2018.08.008

Restrepo-Rodríguez, Andrés Ovidio, Daniel Esteban Casas-Mateus, Paulo Alonso Gaona-García, and Carlos Enrique MontenegroMarín (2019), "Image Recognition Model over Augmented Reality Based on Convolutional Neural Networks through Color-Space Segmentation," in Advances in Computer Vision, K. Arai and S. Kapoor, eds., Cham, Switzerland: Springer, 326-38.

Scholz, Joachim, and Andrew N. Smith (2016), "Augmented Reality: Designing Immersive Experiences That Maximize Consumer Engagement," Business Horizons, 59 (2), 149-61. doi:10.1016/j. bushor.2015.10.003

Schubert, Thomas W. (2009), "A New Conception of Spatial Presence: Once Again, with Feeling," Communication Theory, 19 (2), 161-87. doi:10.1111/j.1468-2885.2009.01340.x

Schwarz, Norbert (2006), "Feelings, Fit, and Funny Effects: A Situated Cognition Perspective," Journal of Marketing Research, 43 (1), 20-23. doi: $10.1509 / \mathrm{jmkr} .43 .1 .20$

Semin, Gün R., and Eliot R. Smith (2013), "Socially Situated Cognition in Perspective," Social Cognition, 31 (2), 125-46. doi:10.1521/soco. 2013.31.2.125

Semmelmann, Kilian, and Sarah Weigelt (2018), "Online Webcam-Based Eye Tracking in Cognitive Science: A First Look," Behavior Research Methods, 50 (2), 451-65. doi:10.3758/s13428-017-0913-7

Stark, Michael, Philipp Lies, Michael Zillich, Jeremy Wyatt, and Bernt Schiele (2008), "Functional Object Class Detection Based on Learned Affordance Cues," in Computer Vision Systems: ICVS 2008. Lecture Notes in Computer Sciences, Antonios Gasteratos, Markus Vincze, and John Tsotsos, eds., Berlin: Springer, 435-44.

Stevens, Ben (2019), "IKEA's AR App Now Lets You Visualise Entire Rooms and Introduces Visual Search," Charged, September 26, https://www.chargedretail.co.uk/2019/09/26/ikeas-ar-app-now-lets-youvisualise-entire-rooms-and-introduces-visual-search/ (accessed January 24, 2020).

Swant, Marty (2019), "Sound May Be the Next Augmented Reality Frontier for Brands," Adweek, April 14, https://www.adweek.com/ digital/sound-may-be-the-next-augmented-reality-frontier-for-brands/ (accessed April 19, 2019).

van der Meulen, Hidde, Andrew L. Kun, and Orit Shaer (2017), "What Are We Missing? Adding Eye-Tracking to the HoloLens to Improve Gaze Estimation Accuracy," in ISS '17: Proceedings of the 2017 ACM International Conference on Interactive Surfaces and Spaces, New York: ACM, 396-400. doi:10.1145/3132272.3132278

van Esch, Patrick, Gavin Northey, Mathew Chylinski, Jonas Heller, Ko de Ruyter, Ashish Sinha, and Tim Hilken (2016), "Augmented Reality: Consumer Saviour or Disruptive Agent in the Retail Power Pendulum?," in Proceedings: Australian and New Zealand Marketing Academy Conference (ANZMAC) 2016: Marketing in a PostDisciplinary Era, Christchurch, New Zealand: University of Canterbury, 728-28.

Villarroel Ordenes, Francisco, Dhruv Grewal, Stephan Ludwig, Ko de Ruyter, Dominik Mahr, and Martin Wetzels (2019), "Cutting through Content Clutter: How Speech and Image Acts Drive Consumer Sharing of Social Media Brand Messages," Journal of Consumer Research, 45 (5), 988-1012. doi:10.1093/jcr/ucy032

Wang, Alex (2007), "Branding over Mobile and Internet advertising: The Cross-Media Effect," International Journal of Mobile Marketing, 2 (1), 34-42.

Wilson, Margaret (2002), "Six Views of Embodied Cognition," Psychonomic Bulletin and Review, 9 (4), 625-36. doi:10.3758/ BF03196322

Wirth, Werner, Tilo Hartmann, Saskia Böcking, Peter Vorderer, Christoph Klimmt, Holger Schramm, Timo Saari, Jari Laarni, Niklas Ravaja, Feliz Ribeiro Gouveia, Frank Biocca, Ana Sacau, Lutz Jäncke, Thomas Baumgartner, and Petra Jäncke (2007), "A Process Model of the Formation of Spatial Presence Experiences," Media Psychology, 9 (3), 493-525. doi:10.1080/15213260701283079

Witmer, Bob G., and Michael J. Singer (1998), "Measuring Presence in Virtual Environments: A Presence Questionnaire," Presence, 7 (3), 225-40. doi:10.1162/105474698565686

Yaoyuneyong, Gallayanee, Jaymye Foster, Erik Johnson, and David Johnson (2016), "Augmented Reality Marketing: Customer Preferences and Attitudes toward Hypermedia Print Ads," Journal of Interactive Advertising, 16 (1), 16-30. doi:10.1080/15252019.2015. 1125316

Yim, Mark Yi-Cheon, Shu-Chuan Chu, and Paul L. Sauer (2017), "Is Augmented Reality Technology an Effective Tool for E-Commerce? An Interactivity and Vividness Perspective," Journal of Interactive Marketing, 39 (August), 89-103. doi:10.1016/j.intmar.2017.04.001

$\mathrm{Yu}$, Donggang, Jesse Sheng Jin, Suhuai Luo, Wei Lai, and Qingming Huang (2010), "A Useful Visualization Technique: A Literature Review for Augmented Reality and Its Application, Limitation, and Future Direction," in Visual Information Communication, M. Huang, Q. Nguyen, and K. Zhang, eds., Boston, MA: Springer, 311-37.

Zhao, Zhenzhen, and Christine Balagué (2015), "Designing Branded Mobile Apps: Fundamentals and Recommendations," Business Horizons, 58 (3), 305-15. doi:10.1016/j.bushor.2015.01.004 